\title{
Effects of a checkpoint kinase inhibitor, AZD7762, on tumor suppression and bone remodeling
}

\author{
LUQI WANG ${ }^{1,2}$, YUE WANG ${ }^{1,2}$, ANDY CHEN $^{2}$, AYDIN JALALI $^{2}$, SHENGZHI LIU $^{1,2}$, YUNXIA GUO $^{1,2}$, \\ SUNGSOO NA ${ }^{2}$, HARIKRISHNA NAKSHATRI ${ }^{3}$, BAI-YAN LI ${ }^{1}$ and HIROKI YOKOTA ${ }^{1,2}$ \\ ${ }^{1}$ Department of Pharmacology, School of Pharmacy, Harbin Medical University, Harbin, Heilongjiang 150081, P.R. China; \\ ${ }^{2}$ Department of Biomedical Engineering, Indiana University-Purdue University Indianapolis; ${ }^{3}$ Department of Surgery, \\ Simon Cancer Research Center, Indiana University School of Medicine, Indianapolis, IN 46202, USA
}

Received February 22, 2018; Accepted June 14, 2018

DOI: $10.3892 /$ ijo.2018.4481

\begin{abstract}
Chemotherapy for suppressing tumor growth and metastasis tends to induce various effects on other organs. Using AZD7762, an inhibitor of checkpoint kinase (Chk) 1 and 2, the present study examined its effect on mammary tumor cells in addition to bone cells (osteoclasts, osteoblasts and osteocytes), using monolayer cell cultures and threedimensional (3D) cell spheroids. The results revealed that AZD7762 blocked the proliferation of 4T1.2 mammary tumor cells and suppressed the development of RAW264.7 pre-osteoclast cells by downregulating nuclear factor of activated T cells cytoplasmic 1 . AZD7762 also promoted the mineralization of MC3T3 osteoblast-like cells and 3D bioprinted bone constructs of MLO-A5 osteocyte spheroids. While a Chk1 inhibitor, PD407824, suppressed the proliferation of tumor cells and the differentiation of pre-osteoclasts, its effect on gene expression in osteoblasts was markedly different compared with AZD7762. Western blotting indicated that the stimulating effect of AZD7762 on osteoblast development was associated with the inhibition of Chk 2 and the downregulation of cellular tumor antigen $\mathrm{p} 53$. The results of the present study indicated that in addition to acting as a tumor suppressor, AZD7762 may prevent bone loss by inhibiting osteoclastogenesis and stimulating osteoblast mineralization.
\end{abstract}

Correspondence to: Dr Hiroki Yokota, Department of Biomedical Engineering, Indiana University-Purdue University Indianapolis, 723 West Michigan Street, SL220, Indianapolis, IN 46202, USA

E-mail: hyokota@iupui.edu

Dr Ban-Yan Li, Department of Pharmacology, School of Pharmacy, Harbin Medical University, 157 Baojian Road, Harbin, Heilongjiang 150081, P.R. China

E-mail: liby@ems.hrbmu.edu.cn

Key words: checkpoint kinase inhibitor, mammary tumor, osteoclasts, osteoblasts

\section{Introduction}

Checkpoint kinases (Chks) are serine/threonine kinases that serve a critical role in cell cycle control, DNA damage responses and cell survival (1). Chks have two subtypes, Chk1 and Chk2, and they are highly conserved from yeast to humans (2). The upregulation of Chks induces cell cycle arrest, while their inhibition in the presence of DNA damage induces abnormal DNA replication, followed by cell death (3). For cancer treatment, inhibitors of Chks are used as chemotherapeutic agents, in many cases with DNA damaging agents (4-6). However, it has been reported that Chk inhibition alone may lead to apoptosis in tumor cells through mutation and/or regulation of cellular tumor antigen p53 (p53) and cyclin-dependent kinase inhibitor 1 (p21) tumor suppressor genes (7). While Chk inhibitors may require delivery to tumor cells, they are able to potentially induce varying responses in other organs. The present study evaluated the effect of AZD7762, a Chk1 and Chk2 inhibitor, on three types of bone cells: Bone-resorbing osteoclasts, bone-forming osteoblasts, and osteocytes.

Breast cancer accounts for $25 \%$ of all cancer cases in women, and advanced breast cancer metastasizes to distant organs, most commonly bone (8). Thus, to treat breast cancer and protect bones from metastasis, the desired function of chemotherapeutic agents is the inhibition of tumor proliferation and osteoclast development. It is also beneficial if the stimulation of osteoblast development is induced. Employing an inhibitor of Chk1 and Chk2, AZD7762 (362 Da), in addition to using PD407824 (328 Da) as a control Chk1 inhibitor, the present study examined their effects on mammary tumor cells, osteoclasts and osteoblasts/osteocytes. AZD7762 is a potent inhibitor of $\mathrm{Chk} 1$ and $\mathrm{Chk} 2$ that potentiates antitumor activity in xenograft models in a dose-dependent manner when simultaneously administered with DNA-damaging agents (9). PD407824 is a selective inhibitor of Chk1 (10), and its inhibitory effect on tumor growth and bone resorption was recently reported in connection to the regulation of stress in the endoplasmic reticulum (ER) (11). Chk1 is a primary gatekeeper of cell division at multiple cell cycle checkpoints, including the $\mathrm{S}, \mathrm{G} 2 / \mathrm{M}$ and $\mathrm{M}$ phases. Chk2 prevents uncontrolled rapid cell division, and inherited mutations in Chk2 are reported to be associated with breast cancer $(12,13)$. The present study 
investigated the common effects of AZD7762 and PD407824 as Chk1 inhibitors, in addition to the differential effects of Chk2 inhibition.

It was previously reported that the elevated phosphorylation of eukaryotic translation initiation factor- $\alpha$ (eIF2 $\alpha$ ) reduces the proliferation of tumor cells and suppresses the differentiation of osteoclasts $(14,15)$. Phosphorylation of eIF2 $\alpha$ is regulated by phosphatases, including protein phosphatase 1 , in addition to four known kinases, including protein kinase RNA-like endoplasmic reticulum kinase (PERK). PERK is activated by stress in the ER (16). Using thapsigargin, an inducer of ER stress, the present study evaluated the role of PERK and eIF $2 \alpha$ in response to AZD7762.

In the present study, the possible multiple roles of AZD7762 in the suppression of tumor growth, inhibition of osteoclast development and stimulation of osteoblast development were investigated. Three bone cell lines were employed [RAW264.7 pre-osteoclast cells (17), MC3T3 osteoblast-like cells (18), and MLO-A5 osteocyte-like cells (19)], together with 4T1.2 mammary tumor cells. The 4T1.2 cell line was isolated from metastasized bone, and represents a breast cancer model of efficient metastasis to bone (20). The responses to AZD7762 and PD407824 were examined in monolayer cell cultures, three-dimensional (3D) spheroids (21), and 3D bio-printed bone constructs (22). While PD407824 is able to inhibit tumor growth and osteoclastogenesis, its ability to promote osteoblast development is limited (11). It has been reported that inhibition of Chk2, and not Chk1, downregulates p53 expression (23). Since p53 is involved in osteoblast development (24), it was hypothesized that besides inhibitory effects on tumor cells and osteoclasts, AZD7762 may have more potent effects on osteoblastogenesis than PD407824 by a p53-dependent pathway.

\section{Materials and methods}

Cell culture. 4T1.2 mouse mammary tumor cells (obtained from Dr R. Anderson at Peter MacCallum Cancer Institute, Melbourne, Australia), MDA-MB-231 human breast cancer cells [American Type Culture Collection (ATCC), Manassas, VA, USA (25)], and MCF-7 human breast cancer cells (26) were cultured in Dulbecco's modified Eagle's medium (Corning Incorporated, Corning, NY, USA). RAW264.7 pre-osteoclast cells (ATCC), MC3T3 osteoblast-like cells (Sigma-Aldrich; Merck KGaA, Darmstadt, Germany), and MLO-A5 osteocytelike cells (obtained from $\mathrm{Dr}$ L. Bonewald at Indiana University, Indianapolis, IN, USA) were grown in $\alpha$ minimum essential medium (MEM; Gibco; Thermo Fisher Scientific. Inc., Waltham, MA, USA). Bone marrow-derived cells, obtained by flushing the tibia and femur from one female 10 -week old BALB/c mouse and separating with low-density gradient centrifugation (27), were cultured in $\alpha$ MEM with $10 \mathrm{ng} / \mathrm{ml}$ macrophage colony-stimulating factor (PeproTech, Inc., Rocky Hill, NJ, USA) for 2 days, and the surface-attached cells were used as osteoclast precursors. The experimental procedures using animals were approved by the Indiana University Animal Care and Use Committee and were in compliance with the Guiding Principles in the Care and Use of Animals endorsed by the American Physiological Society (28). The culture media contained 10\% fetal bovine serum (FBS; Atlanta Biologicals, Flowery Branch, GA, USA) and antibiotics $(50 \mathrm{U} / \mathrm{ml}$ penicillin and $50 \mu \mathrm{g} / \mathrm{ml}$ streptomycin; Life Technologies; Thermo Fisher Scientific, Inc.). MLO-A5 cells were grown with 5\% FBS and $5 \%$ bovine calf serum. Cells were maintained at $37^{\circ} \mathrm{C}$ and $5 \%$ $\mathrm{CO}_{2}$ in a humidified incubator, and treated with AZD7762 (0.1-10 $\mu \mathrm{M})$, PD407824 $(0.1-20 \mu \mathrm{M})$, or thapsigargin $(1 \mu \mathrm{M}$; Tocris Bioscience, Bristol, UK).

Cellular proliferation was evaluated using an MTT assay (Sigma-Aldrich; Merck KGaA), according to the manufacturer's protocol. The relative cell proliferation was determined as a ratio of the absorbance at $570 \mathrm{~nm}$ of each sample and control, as measured using a plate reader. To quantify $3 \mathrm{D}$ spheroid cell viability, the CellTiter-Glo 3D Cell Viability Assay (Promega Corporation, Madison, WI, USA) was used, according to the manufacturer's protocol, measuring luminescence with a plate reader.

$3 D$ spheroid assay and $3 D$ bio-printing. To induce spheroid formation, 5,000 cells were cultured in a U-bottom lowadhesion 96-well plate (S-Bio, Hudson, NH, USA). MLO-A5 osteocyte spheroids were bio-printed onto a needle array using a Regenova 3D Bioprinter (Cyfuse Biomedical K.K., Tokyo, Japan) (22) to generate bone constructs mineralized in osteogenic medium (70 $\mu \mathrm{M}$ ascorbic acid and $5 \mathrm{mM}$ $\beta$-glycerophosphate) (27). Each construct contained 18 osteocyte spheroids ( $3 \times 3 \times 2$ configuration).

Motility assay. To evaluate motility in a monolayer culture, a wound healing scratch motility assay was performed as described previously (29). In brief, cells were plated in 12-well plates and, the following day, scratching was performed using a plastic tip. The areas newly occupied with cells in the scratched zone were determined $24 \mathrm{~h}$ post-scratching using images obtained using a microscope (magnification, $\mathrm{x} 40$; Nikon Eclipse TS100, Nikon Corporation, Tokyo, Japan), which were scanned using Adobe Photoshop (CS2; Adobe Systems, Inc., San Jose, CA, USA) and quantified with Image J v1.51p (National Institutes of Health, Bethesda, MD, USA).

Osteoclast differentiation assay and pit formation assay. Using RAW264.7 pre-osteoclast cells, an osteoclast differentiation assay was conducted in 24-well plates with $30 \mathrm{ng} /$ $\mathrm{ml}$ receptor activator of nuclear factor- $\mathrm{KB}$ ligand (RANKL) in the presence and absence of 0.1-2 $\mu \mathrm{M}$ AZD7762 and PD407824. For bone marrow-derived cells, cells were cultured in $10 \mathrm{ng} / \mathrm{ml}$ macrophage colony stimulating factor (M-CSF; Peprotech, Inc., Rocky Hill, NJ, USA) for 2 days prior to the addition of RANKL (27). During the 5-day experiments, the culture medium was replaced once on day 3 . Adherent cells were fixed with a citrate, acetone and formaldehyde solution for $30 \mathrm{sec}$ at room temperature and stained for $20 \mathrm{~min}$ at $37^{\circ} \mathrm{C}$ with a tartrate resistant acid phosphate (TRAP)-staining kit, according to the manufacturer's protocol (Sigma-Aldrich; Merck KGaA). TRAP-positive multinucleated cells ( $>3$ nuclei) were identified as mature osteoclasts (30).

A pit formation assay was conducted similarly using 24-well culture plates coated with hydroxyapatite (31). After 6 days, cells were removed with $5 \%$ sodium hypochlorite for $5 \mathrm{~min}$ at room temperature, and images of the wells were captured with a phase-contrast inverted microscope at $\mathrm{x} 40$ magnification. Using ImageJ, the areas of the wells no longer coated with 
Table I. Reverse transcription-quantitative polymerase chain reaction primers used in the present study.

\begin{tabular}{lll}
\hline Target & Forward primer & \multicolumn{1}{c}{ Reverse primer } \\
\hline ALP & 5'-CTGACTGACCCTTCGCTCTC-3' & 5'-GGTCAATCCTGCCTCCTTCC-3' \\
OCN & 5'-CCGGGAGCAGTGTGAGCTTA-3' & 5'-AGGCGGTCTTCAAGCCATACT-3' \\
Osterix & 5'-CCCTTCTCAAGCACCAATGG-3' & 5'-AGGGTGGGTAGTCATTTGCATAG-3' \\
GAPDH & 5'-TGCACCACCAACTGCTTAG-3' & 5'-GGATGCAGGGATGATGTTC-3' \\
\hline
\end{tabular}

ALP, alkaline phosphatase; OCN, osteocalcin.

hydroxyapatite were measured, and the pit area fraction was calculated by normalizing to the total image area.

Alizarin red staining. MC3T3 cells were seeded on 24-well tissue-culture plates at $6.5 \times 10^{4}$ cells/well. Upon becoming fully confluent, osteogenic medium $(70 \mu \mathrm{M}$ ascorbic acid and $5 \mathrm{mM}$ $\beta$-glycerophosphate) was added, with 0-0.5 $\mu \mathrm{M}$ AZD7762, and the cells were cultured for 5 weeks, changing the media every other day. The effect of AZD7762 on mineralization was evaluated by staining at room temperature for $3 \mathrm{~min}$ with $1 \%$ Alizarin Red S solution (Sigma-Aldrich; Merck KGaA) and imaged at x40 magnification with an inverted microscope. Alizarin red staining was quantified by measuring the image grey-scale values using Image J.

Reverse transcription-quantitative polymerase chain reaction (RT-qPCR) and RNA interference. Total RNA was extracted using an RNeasy Plus mini kit (Qiagen, Inc., Valencia, CA, USA) and RT was conducted $\left(37^{\circ} \mathrm{C}\right.$ for $2 \mathrm{~h} ; 85^{\circ} \mathrm{C}$ for $\left.5 \mathrm{~min}\right)$ with a high-capacity cDNA reverse transcription kit (Applied Biosystems; Thermo Fisher Scientific, Inc.). RT-qPCR was performed using Power SYBR green PCR master mix kits (Applied Biosystems; Thermo Fisher Scientific, Inc.) with the PCR primers listed in Table I. RNA interference was conducted using small interfering (si)RNA specific to PERK (cat. no. 100334), Chk1 (cat. no. 160184) and Chk2 (cat. no. 78549; Life Technologies; Thermo Fisher Scientific, Inc.). A negative siRNA (Silencer Select \#1; Life Technologies; Thermo Fisher Scientific, Inc.) was used as a nonspecific negative control. Cells were transiently transfected with siRNA (130 pmol per 6-cm dish) using Lipofectamine ${ }^{\circledR}$ RNAiMAX (Life Technologies; Thermo Fisher Scientific, Inc.) in Opti-MEM I medium. The medium was replaced with regular culture medium after $24 \mathrm{~h}$, and the silencing efficiency was measured by immunoblotting $48 \mathrm{~h}$ post-transfection.

Western blot analysis. Cells were lysed in a radioimmunoprecipitation assay buffer with protease inhibitors (Santa Cruz Biotechnology, Inc., Dallas, TX, USA) and phosphatase inhibitors (Calbiochem; Merck KGaA). Following measuring of the protein concentration using a Bicinchoninic Acid Protein Assay kit (Thermo Fisher Scientific, Inc.), $\sim 10 \mu \mathrm{g}$ isolated proteins/lane were fractionated using 10-15\% SDS gels and electrotransferred to polyvinylidene difluoride membranes (EMD Millipore, Billerica, MA, USA). Membranes were blocked in $2 \%$ blotting-grade blocker (BioRad Laboratories, Inc., Hercules, CA, USA) for $1 \mathrm{~h}$ at room temperature or overnight at $4^{\circ} \mathrm{C}$. Antibodies against alkaline phosphate (cat. no. sc-28904; Santa Cruz Biotechnology, Inc.), cathepsin K (cat. no. sc-48353; Santa Cruz Biotechnology, Inc.), PERK (cat. no. sc-13073; Santa Cruz Biotechnology, Inc.), nuclear factor of activated $\mathrm{T}$ cells cytoplasmic 1 (NFATc1; cat. no. sc-7294; Santa Cruz Biotechnology, Inc.), Chk1 (cat. no. 2360; Cell Signaling Technology, Inc., Danvers, MA, USA), phosphorylated (p)-Chk1 (cat. no. 90178; Cell Signaling Technology, Inc.), Chk2 (cat. no. 2662; Cell Signaling Technology, Inc.), eIF $2 \alpha$ (cat. no. 9722; Cell Signaling Technology, Inc.), p-eIF2 $\alpha$ (cat. no. 9721; Cell Signaling Technology, Inc.), microtubule-associated proteins 1A/1B light chain (LC)3A/B II (cat. no. 4108; Cell Signaling Technology, Inc.), caspase 3 (cat. no. 9662; Cell Signaling Technology, Inc.), cleaved caspase 3 (cat. no. 9661; Cell Signaling Technology, Inc.), p38 (cat. no. 9212; Cell Signaling Technology, Inc.), p-p38 (cat. no. 9211; Cell Signaling Technology, Inc.), p-PERK (cat. no. 3179; Cell Signaling Technology, Inc.), p53 (cat. no. MA5-12557; Invitrogen; Thermo Fisher Scientific, Inc.), p-Chk2 (cat. no. SAB4504366; Invitrogen; Thermo Fisher Scientific, Inc.), and $\beta$-actin (cat. no. A5441; SigmaAldrich; Merck KGaA) were used. Primary antibodies were incubated for $1 \mathrm{~h}$ at room temperature or overnight at $4^{\circ} \mathrm{C}$ at a 1:1,000 dilution, except Chk2, p-Chk2, p-PERK (all 1:500), p53 (1:200) and $\beta$-actin $(1: 10,000)$, while anti-rabbit (cat. no. 7074; Cell Signaling Technology, Inc.) and anti-mouse (cat. no. 7076; Cell Signaling Technology, Inc.) secondary antibodies were incubated for $45 \mathrm{~min}$ at room temperature at a 1:2,000 dilution. Protein expression levels were assayed using a SuperSignal west femto maximum sensitivity substrate (Thermo Fisher Scientific, Inc.).

Fluorescence resonance energy transfer (FRET) imaging. To evaluate the potential role of GTPases in cellular motility, the activity of RhoA GTPase was determined by FRET imaging. In response to $2 \mu \mathrm{M}$ AZD7762 and PD407824, energy transfer was measured in a RhoA-specific cyan fluorescent protein (CFP)-yellow fluorescent protein (YFP) biosensor (32). The filter sets (Semrock; IDEX Health \& Science, LLC, Rochester, NY, USA) were chosen for CFP excitation at $438 \pm 24 \mathrm{~nm}$ (center wavelength \pm bandwidth), CFP emission at $483 \pm 32 \mathrm{~nm}$ and YFP emission at $542 \pm 27 \mathrm{~nm}$. Using a fluorescence microscope (Nikon Corporation, Tokyo, Japan) time-lapse images were acquired at an interval of $5 \mathrm{~min}$. The emission ratio of YFP/CFP for individual cells was computed to determining the activity levels using NIS-Elements software v3.2 (Nikon Corporation). 


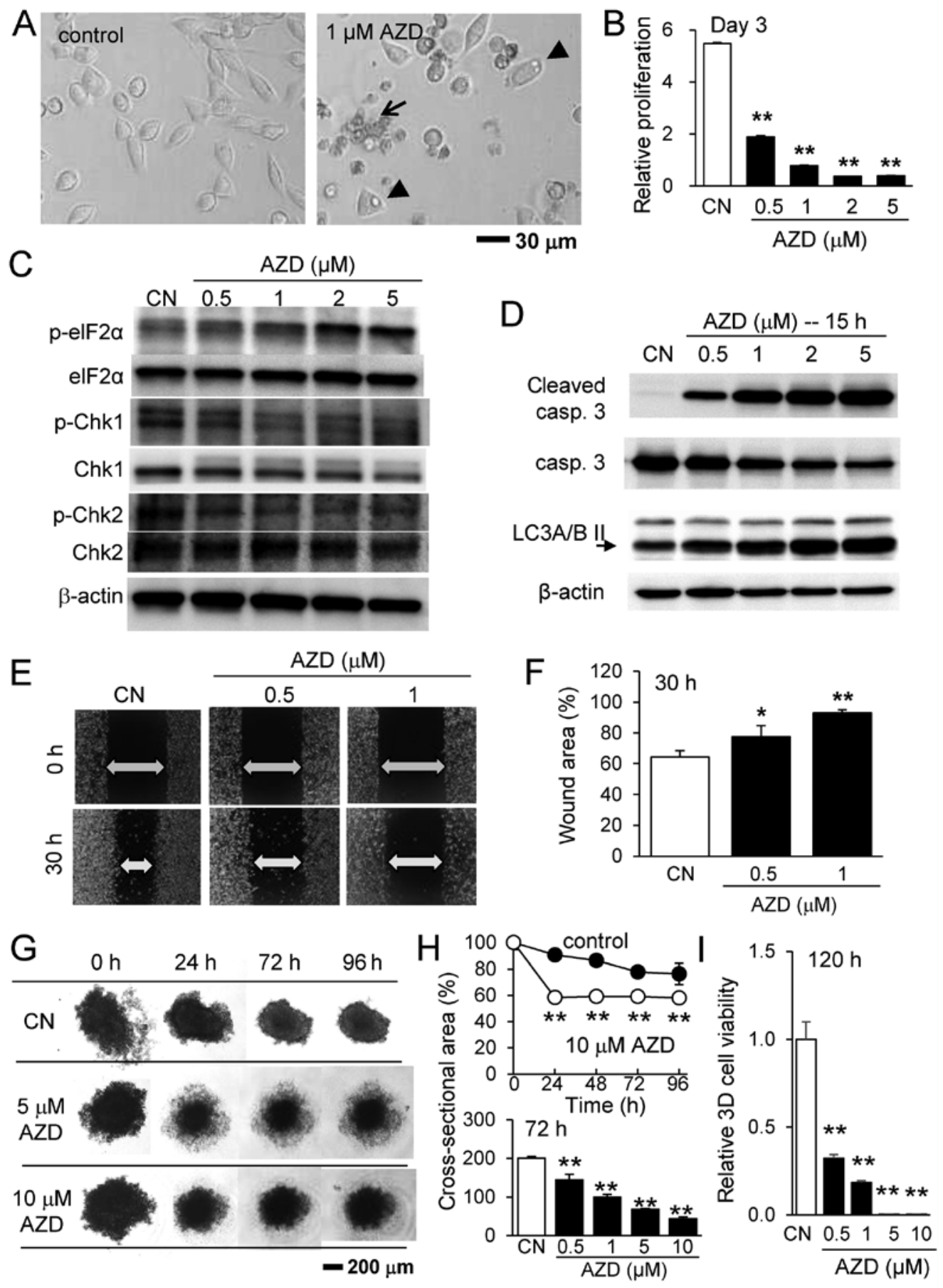

Figure 1. Inhibitory effects of AZD7762 on 4T1.2 mammary tumor cells. (A) Representative images of 4T1.2 cells in response to $1 \mu \mathrm{M}$ AZD7762 for $24 \mathrm{~h}$. The arrow and arrow heads indicate apoptotic and autophagic cells, respectively, assessed according to cellular morphology. (B) Relative proliferation of $4 \mathrm{~T} 1.2$ cells in response to $0.5,1,2$ and $5 \mu \mathrm{M}$ AZD7762. (C) Upregulation of p-eIF2 $\alpha$, and downregulation of p-Chk1 and p-Chk2. (D) Upregulation of cleaved caspase 3 (apoptosis marker) and LC3A/B II (autophagy marker). (E) Scratch assay and (F) wound area in response to 0.5 and $1 \mu \mathrm{M} \mathrm{AZD7762.} \mathrm{(G)} \mathrm{3D} \mathrm{tumor}$ spheroids in response to 5 and $10 \mu \mathrm{M}$ AZD7762. (H) Cross-sectional area and (I) cell viability of 3D tumor spheroids in response to AZD7762. "P<0.05; ${ }^{* *} \mathrm{P}<0.01$ vs. CN. CN, control; AZD, AZD7762; 3D, three-dimensional; eIF2 $\alpha$, eukaryotic translation initiation factor- $\alpha$; p, phosphorylated; Chk, checkpoint kinase inhibitor, casp, caspase; LC3A/B II, microtubule-associated proteins 1A/1B light chain 3A/B II.

Micro-computed tomography (CT) imaging. Micro-CT was performed using Skyscan 1172 (Bruker-MicroCT, Kontich, Belgium) (33). The printed bone constructs were wrapped in Parafilm to maintain hydration and placed in a plastic tube. Scans were performed at pixel size $6 \mu \mathrm{m}$. Using manufacturerprovided software, the images were reconstructed (nRecon v1.6.9.18), rotated (DataViewer v1.5.0), and the bone mineral density of the mineralized bone construct was determined by calculating the mean attenuation coefficient and calibrated to two hydroxyapatite phantoms of known density (CTAn v1.11.4.2).

Statistical analysis. The data are expressed as the mean \pm standard deviation of three to four replicates. One-way analysis of variance was employed to examine the statistical significance among groups, and Fisher's protected least significant 


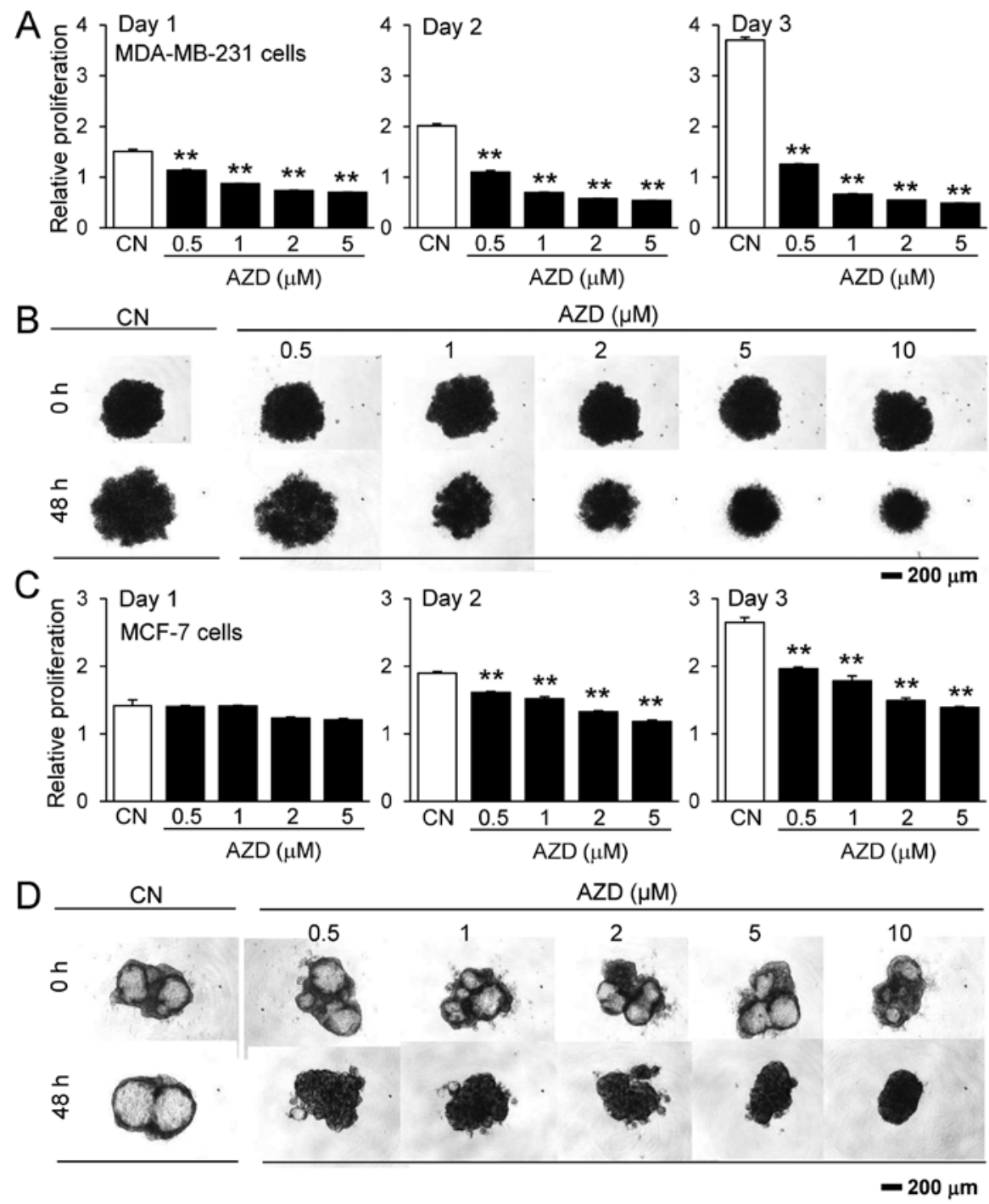

Figure 2. Inhibitory effects of AZD7762 on MDA-MB-231 and MCF-7 breast cancer cells. (A) Relative proliferation of MDA-MB-231 cells in response to AZD7762 on days 1-3. (B) Dose-dependent shrinkage of MDA-MB-231 tumor spheroids by AZD7762. (C) Relative proliferation of MCF-7 cells in response to AZD7762 on days 1-3. (D) Dose-dependent shrinkage of MCF-7 tumor spheroids by AZD7762. " P<0.01 vs. CN. CN, control; AZD, AZD7762.

difference was conducted as a post hoc test to evaluate the pairwise comparisons using R 3.4.3 (R Foundation for Statistical Computing, Vienna, Austria). $\mathrm{P}<0.05$ was considered to indicate a statistically significant difference.

\section{Results}

Inhibitory effects of AZD7762 on 4 T1.2 mammary tumor cells. The present study first examined the effects of AZD7762, an inhibitor of Chk1 and Chk2, on the proliferation and migration of 4T1.2 mammary tumor cells. As the representative images of $4 \mathrm{~T} 1.2$ cells illustrate, in response to $1 \mu \mathrm{M}$ AZD7762, the cells underwent apoptosis (blebbing and cell shrinkage) and autophagy (increase in vacuole-like structures in the cytoplasm and membrane expansion), and the relative proliferation of the tumor cells was significantly reduced in a dose-dependent manner (Fig. 1A and B). Western blot analysis revealed that p-eIF $2 \alpha$ was elevated in addition to cleaved caspase 3 (apoptosis marker) and LC3A/B II (autophagy marker) (Fig. 1C and D), while the expression levels of $\mathrm{p}-\mathrm{Chk} 1$ and $\mathrm{p}-\mathrm{Chk} 2$ were reduced. The scratch assay for examining cellular motility demonstrated that the healing of the wound area was decreased by 0.5 and $1 \mu \mathrm{M}$ AZD7762 (Fig. 1E and $F$ ), indicating that AZD7762 reduces the motility of tumor cells. Notably, the wound area was also enlarged as a result of AZD7762-driven cell death.

Since tumor growth may differ according to the culture conditions, the present study subsequently examined the effects of AZD7762 on 3D spheroids solely composed of 4T1.2 cells (Fig. 1G). Initially, the spheroids were irregularly shaped with a rough surface. They gradually compacted, forming a necrotic core at the center and a quiescent shell around the core with a proliferating surface. In response to 0.5 to $10 \mu \mathrm{M}$ AZD7762, the spheroids significantly altered in appearance. While the spheroids exhibited extended quiescent zones at the lower concentrations ( 0.5 and $1 \mu \mathrm{M}$ AZD7762), it increased the necrotic core at the higher concentrations (5 and $10 \mu \mathrm{M}$ AZD7762). AZD7762 reduced the cross-sectional area of the tumor spheroids and decreased 3D cell viability (Fig. $1 \mathrm{H}$ and I).

To evaluate its effect on other types of breast cancer, the present study also examined the responses of two human 

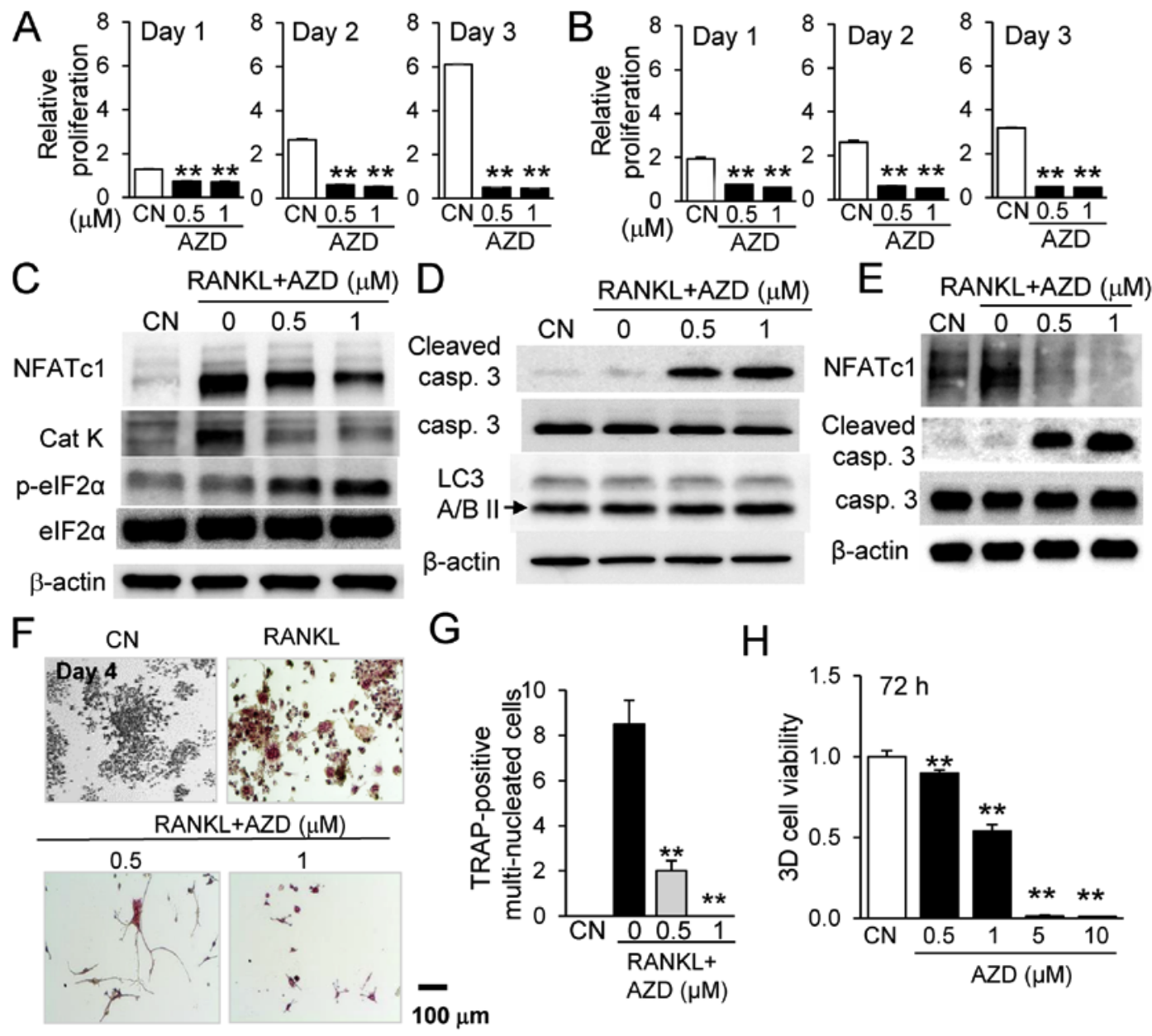

$\mathrm{H}$
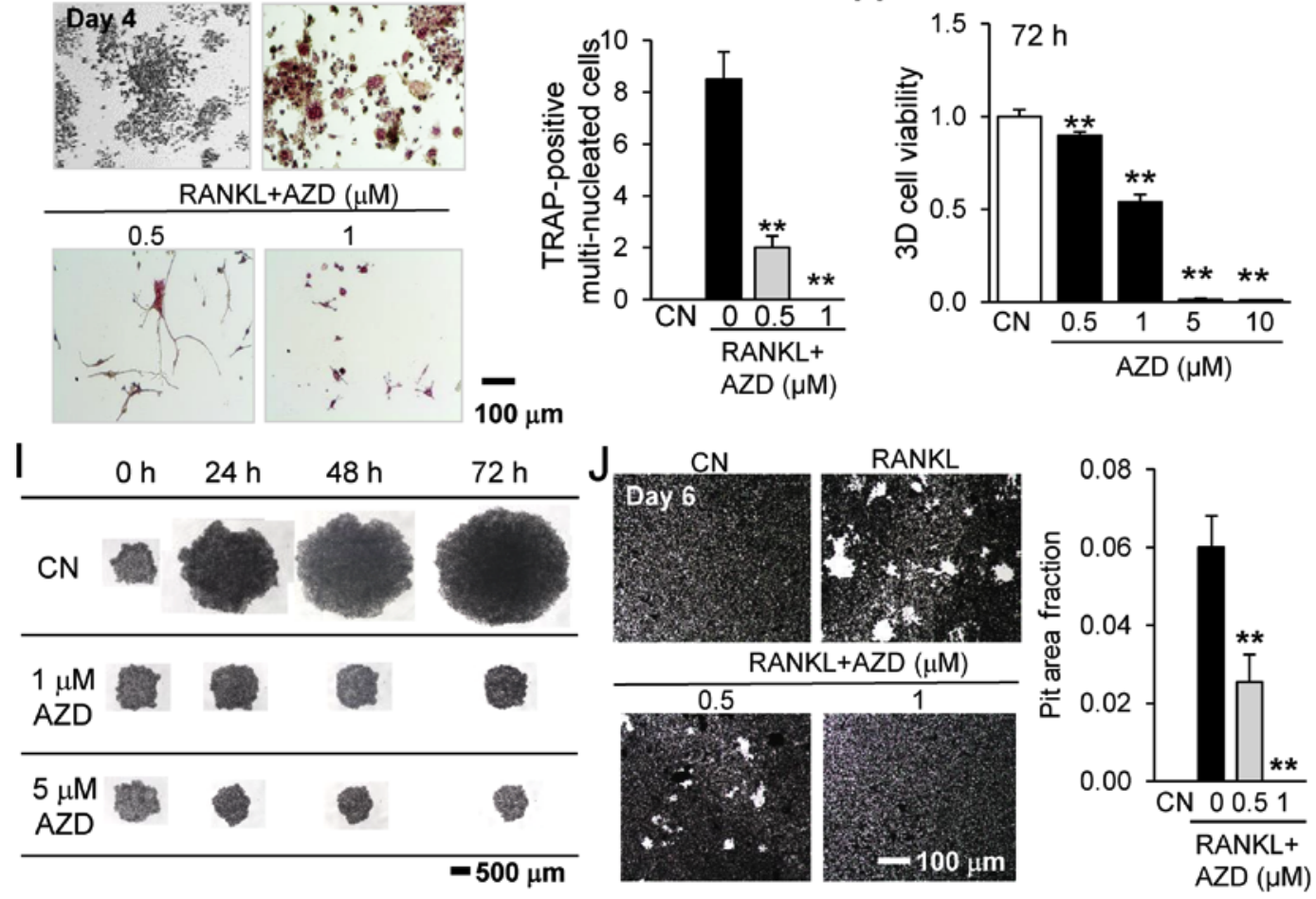

Figure 3. Inhibitory effects of AZD7762 on RAW264.7 pre-osteoclast cells and osteoclast precursors from bone marrow-derived cells. Relative proliferation of (A) RAW264.7 cells and (B) osteoclast precursors from bone marrow-derived cells in response to 0.5 and $1 \mu$ M AZD7762 on days 1, 2 and 3 , respectively. (C) Downregulation of NFATc1 and Cat K, and upregulation of p-eIF2 $\alpha$ in RAW cells. (D) Upregulation of cleaved caspase 3 in RAW cells. (E) Downregulation of NFATc1 and upregulation of cleaved caspase 3 in osteoclast precursors from bone marrow-derived cells. (F) Visualization and (G) quantification of the reduction in the number of multi-nucleated TRAP-positive osteoclast cells in response to 0.5 and $1 \mu \mathrm{M}$ AZD7762. (H) Dose-dependent reduction in 3D cell viability in RAW264.7 spheroids. (I) RAW264.7 spheroids in response to $0.5,1,5$ and $10 \mu \mathrm{M}$ AZD7762 for 24,48 and 72 h. (J) Reduction of osteoclast activity by 0.5 and $1 \mu \mathrm{M}$ AZD7762. ${ }^{* *} \mathrm{P}<0.01 \mathrm{vs}$. CN. CN, control; AZD, AZD7762; Cat K, cathepsin K; casp, caspase; eIF2 $\alpha$, eukaryotic translation initiation factor- $\alpha$; RANKL, receptor activator of nuclear factor- $\kappa \mathrm{B}$ ligand; $3 \mathrm{D}$, three-dimensional; NFATc1, nuclear factor of activated T cells cytoplasmic 1; LC3A/B II, microtubule-associated proteins 1A/1B light chain 3A/B II.

breast cancer cell lines, MDA-MB-231 and MCF-7, to AZD7762. MDA-MB-231 cells are estrogen receptor-negative, while MCF-7 cells are estrogen receptor-positive. The results revealed that AZD7762 inhibited the proliferation of the two cell lines, as measured by MTT assay, in a monolayer cell culture, and decreased the sizes of the 3D tumor spheroids, although 4T1.2 and MDA-MB-231 cells were more sensitive to AZD7762 compared with MCF-7 cells (Fig. 2).
Inhibitory effects of AZD7762 on RAW264.7 pre-osteoclast cells. Osteoclasts serve a pivotal role in bone homeostasis. Using RAW264.7 pre-osteoclast cells and osteoclast precursors from bone marrow-derived cells, the present study evaluated the effect of AZD7762 on the proliferation and differentiation of osteoclasts. Treatment with AZD7762 significantly reduced the proliferation of RAW264.7 cells and primary osteoclast precursors (Fig. 3A and B). The half-maximal inhibitory 


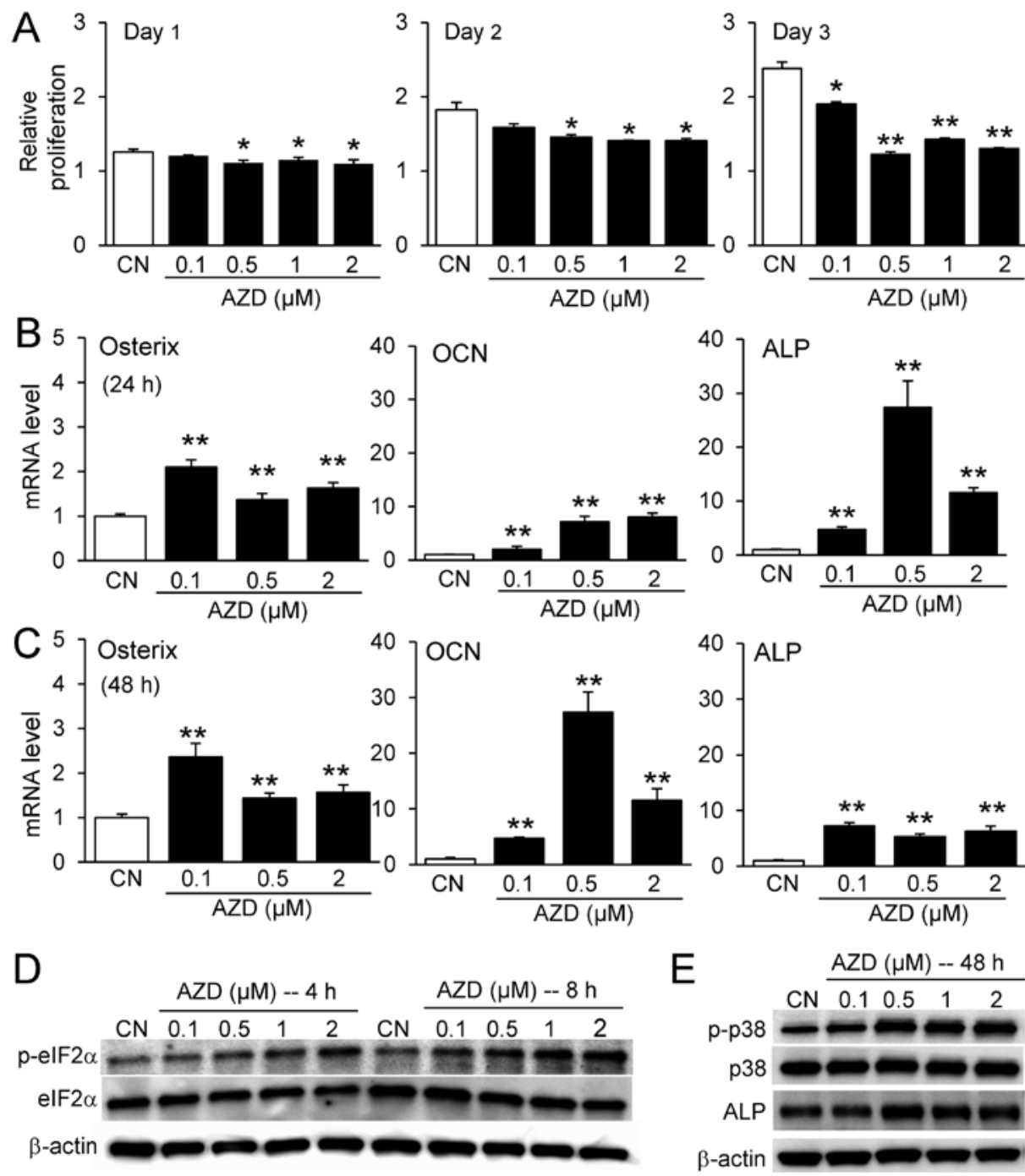

Figure 4. Responses of MC3T3 osteoblast-like cells to AZD7762. (A) Relative proliferation of MC3T3 cells in response to 0.1, 0.5, 1, and $2 \mu$ M AZD7762 on days 1,2 , and 3. Increase in the mRNA expression levels of osterix, OCN, and ALP in response to 0.1, 0.5, and $2 \mu \mathrm{M}$ AZD7762 at (B) $24 \mathrm{~h}$ and (C) $48 \mathrm{~h}$. (D) Elevation of p-eIF2 $\alpha$, (E) p-p38 and ALP in response to 0.1, 0.5, 1, and $2 \mu \mathrm{M}$ AZD7762. " $\mathrm{P}<0.05$; ${ }^{* *} \mathrm{P}<0.01$ vs. CN. CN, control; AZD, AZD7762; OCN, osteocalcin; ALP, alkaline phosphatase; p, phosphorylated; eIF2 $\alpha$, eukaryotic translation initiation factor- $\alpha$.

concentration for AZD7762 in bone marrow-derived osteoclasts was estimated as $0.54 \mu \mathrm{M}$ by fitting an exponential curve to the MTT results (data not shown). In RAW cells, AZD7762 also downregulated NFATc1, a master transcription factor for osteoclastogenesis, in addition to cathepsin $\mathrm{K}$, a marker of bone resorption (Fig. 3C). It was additionally observed that the expression level of p-eIF $2 \alpha$ was elevated, together with cleaved caspase 3, in RAW cells (Fig. 3C and D). In primary osteoclast precursors, AZD7762 suppressed the RANKL-driven upregulation of NFATc1 and elevated cleaved caspase 3 expression (Fig. 3E). As demonstrated by TRAP staining for identifying multi-nucleated osteoclasts, AZD7762 significantly reduced the number of multi-nucleated TRAP-positive osteoclast cells in a dose-dependent manner (Fig. 3F and G). Furthermore, AZD7762 decreased the 3D cell viability of RAW264.7 spheroids in a dose-dependent manner (Fig. 3H). Consistent with the inhibitory effect of AZD7762 on RAW264.7 cultured cells, AZD7762 at $0.5,1,5$ and $10 \mu \mathrm{M}$ decreased the cross-sectional area of RAW264.7 spheroids at 24-72 h (Fig. 3I). Finally, osteoclast activity measured by a pit formation assay was reduced by 0.5 and $1 \mu \mathrm{M}$ AZD7762 (Fig. 3J).

Development of MC3T3 osteoblast-like cells in response to AZD7762. The present study additionally examined the effect of AZD7762 on osteoblast activity. AZD7762 reduced the relative proliferation of MC3T3 osteoblast-like cells in response to $0.1,0.5,1$ and $2 \mu \mathrm{M}$, although the degree of reduction was smaller compared with RAW264.7 pre-osteoclast cells (Fig. 4A). AZD7762 increased the mRNA levels of osteogenesis-associated genes, including osterix, osteocalcin (OCN), and alkaline phosphatase (ALP) at 24 and $48 \mathrm{~h}$ (Fig. 4B and C); it also elevated the protein expression levels of p-eIF2 $\alpha$, p-p38 and ALP (Fig. 4D and E).

Comparison of the effect of AZD7762 and PD407824 on tumor cells. In order to evaluate any differential effects of Chk1 and Chk2 inhibition, PD407824, a selective inhibitor of Chk1, was used. The responses to PD407824 were largely similar to those to AZD7762. PD407824 at $0.1,0.5$ and $2 \mu \mathrm{M}$ reduced 

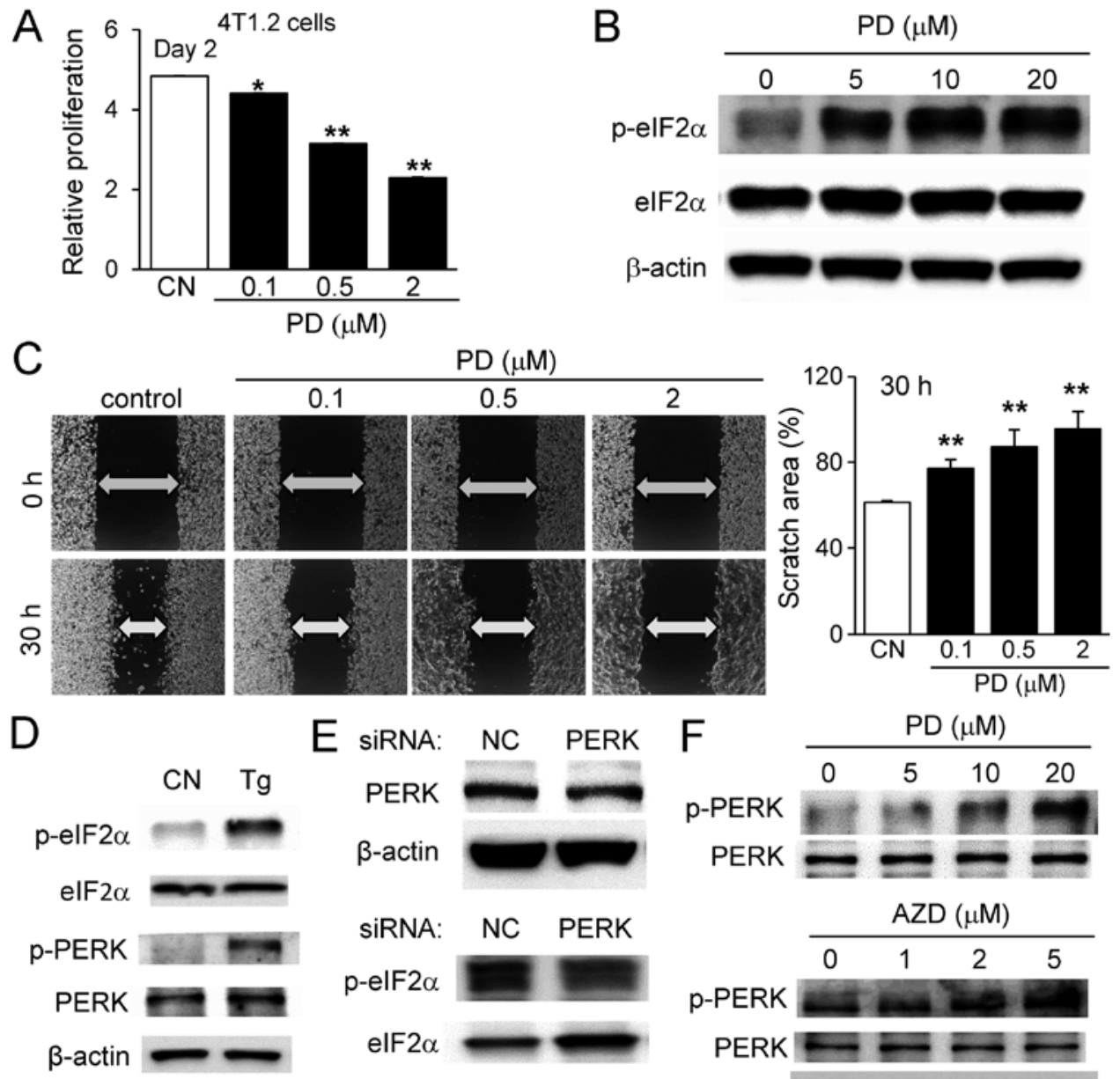

E siRNA: NC PERK

$F$
p-PERK
PERK

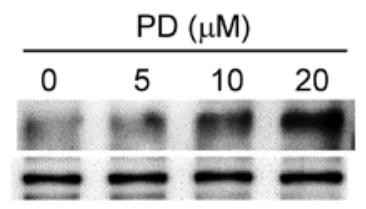

$\beta$-actin
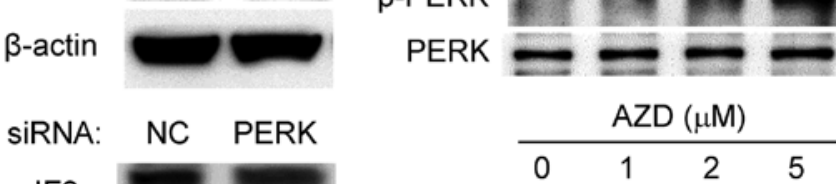

p-elF2 $\alpha$

elF $2 \alpha$

p-PERK

PERK

$\beta$-actin
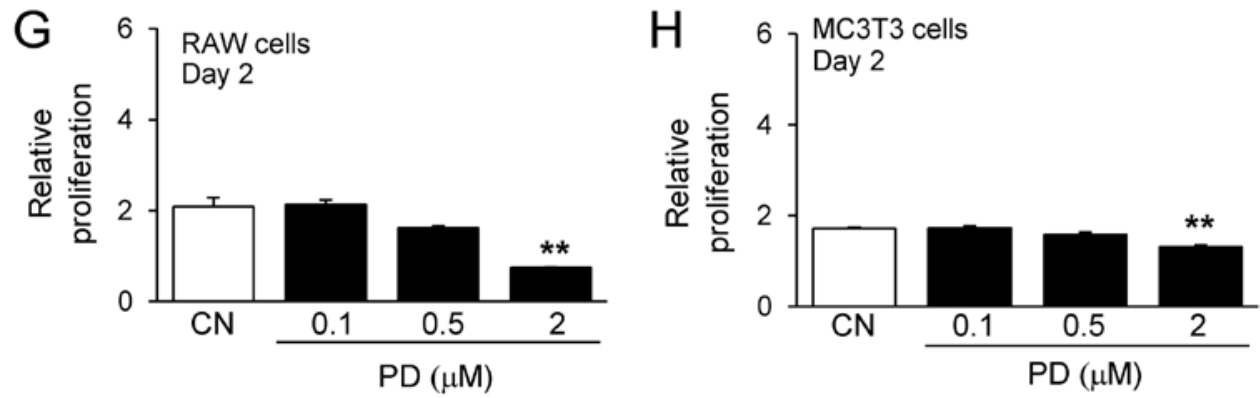

Figure 5. Effects of PD407824 and AZD7762 on 4T1.2 tumor cells, RAW264.7 pre-osteoclast cells and MC3T3 osteoblast-like cells. (A) Relative proliferation of 4T1.2 cells in response to $0.1,0.5$, and $2 \mu \mathrm{M}$ PD407824 on day 2. (B) Upregulation of p-eIF2 $\alpha$ by PD407824. (C) Scratch assay of 4T1.2 cells in response to $0.1,0.5$, and $2 \mu \mathrm{M}$ PD407824. (D) Elevation of p-eIF2 $\alpha$ and p-PERK by Tg. (E) Downregulation of p-eIF2 $\alpha$ by PERK siRNA. (F) Upregulation of p-PERK by PD407824 and AZD7762. Relative proliferation of (G) RAW264.7 cells and (H) MC3T3 cells, respectively, in response to 0.1, 0.5 , and $2 \mu \mathrm{M}$ PD407824 on day 2. ${ }^{* *}$ P $<0.01$ vs. CN. CN, control; AZD, AZD7762; p, phosphorylated; eIF2 $\alpha$, eukaryotic translation initiation factor- $\alpha$; PERK, protein kinase RNA-like endoplasmic reticulum kinase; Tg, thapsigargin; siRNA, small interfering RNA; PD, PD407824.

the relative proliferation of $4 \mathrm{~T} 1.2$ cells (Fig. 5A), and the expression level of p-eIF $2 \alpha$ was elevated in a dose-dependent manner (Fig. 5B). Furthermore, the scratch assay with 4T1.2 mammary tumor cells revealed that PD407824 suppressed cell motility by inhibiting the healing of the wounded area (Fig. 5C). To evaluate the potential mechanism of p-eIF $2 \alpha$ upregulation, the expression of p-PERK, a kinase induced by stress to the (ER), was evaluated. First, thapsigargin, an ER stress inducer, elevated p-eIF2 $\alpha$ and p-PERK expression after $3 \mathrm{~h}$ of incubation (Fig. 5D). Second, partial silencing of PERK by RNA interference downregulated p-eIF2 $\alpha$ (Fig. 5E), and PD407824 and AZD7762 elevated the expression level of p-PERK (Fig. 5F). Collectively, these data indicated that the elevation of p-eIF $2 \alpha$ may be induced by p-PERK, an eIF $2 \alpha$ selective kinase.

Effects of PD407824 on osteoclasts and osteoblasts. In addition to its effect on tumor cells, PD407824 affects RAW264.7 pre-osteoclasts similarly to AZD7762. PD407824 at 0.1, 0.5 and $2 \mu \mathrm{M}$ reduced the relative proliferation of RAW264.7 cells (Fig. 5G). In MC3T3 cells, PD407824 at 0.1 and $0.5 \mu \mathrm{M}$ did not significantly alter the relative cell proliferation, although a 


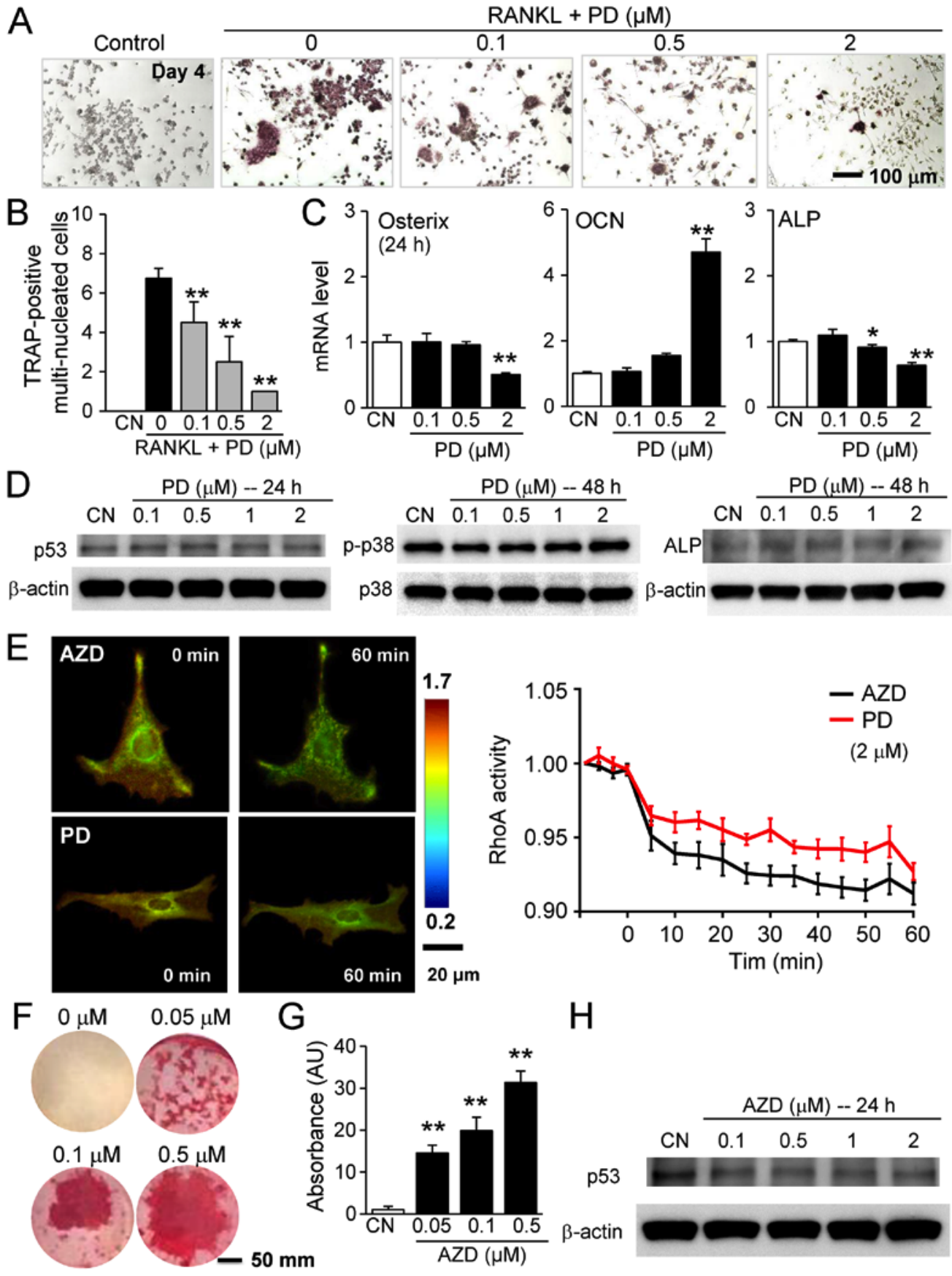

Figure 6. Effects of PD407824 and AZD7762 on RAW264.7 pre-osteoclast cells and MC3T3 osteoblast-like cells. (A) Suppression of RANKL-driven differentiation of RAW264.7 cells by $0.1,0.5$, and $2 \mu \mathrm{M}$ PD407824, as demonstrated by (B) the numbers of TRAP-positive multinucleated cells. (C) Alterations in the mRNA expression levels of osterix, OCN and ALP by $0.1,0.5$, and $2 \mu \mathrm{M}$ PD407824. (D) No significant alterations were observed in the protein expression levels of p53, p-p38 and ALP in response to 0.1 to $2 \mu \mathrm{M}$ PD407824. (E) Reduction in RhoA activity in MC3T3 cells in response to $2 \mu \mathrm{M}$ AZD7762 and PD407824. (F) Alizarin red staining of mineralized MC3T3 cells in response to $0.05,0.1$, and $0.5 \mu \mathrm{M}$ AZD7762 for 5 weeks. (G) Dose-dependent intensity of alizarin red staining by AZD7762. (H) Downregulation of p53 by AZD7762. $\mathrm{P}<0.05 ;{ }^{* *} \mathrm{P}<0.01$ vs. CN. CN, control; AZD, AZD7762; PD, PD407824; OCN, osteocalcin; ALP, alkaline phosphatase; TRAP, tartrate resistant acid phosphate; p, phosphorylated; p53, cellular tumor antigen p53.

higher dosage of $2 \mu \mathrm{M}$ decreased the number of MC3T3 cells (Fig. 5H). The RANKL-driven differentiation of RAW264.7 cells was also suppressed by $0.1,0.5$ and $2 \mu \mathrm{M}$ PD407824 in a dose-dependent manner (Fig. 6A and B).

Mineralization of MC3T3 and MLO-A5 cells by AZD7762. A major difference between AZD7762 and PD407824 was their effects on genes involved in bone formation. While AZD7762 elevated the mRNA expression levels of osterix and ALP,
PD407824 at $2 \mu \mathrm{M}$ reduced their expression levels (Fig. 6C). Furthermore, the effect of PD407824 on the protein expression levels of p53, p-p38, and ALP was not notable (Fig. 6D). To evaluate the potential involvement of RhoA GTPase in the regulation of cellular motility with Chk1 inhibitors, its activity level was evaluated using a RhoA GTPase FRET biosensor. In response to $2 \mu \mathrm{M}$ AZD7762 and PD407824, significant reductions in RhoA activity were observed after 60 min (Fig. 6E). 


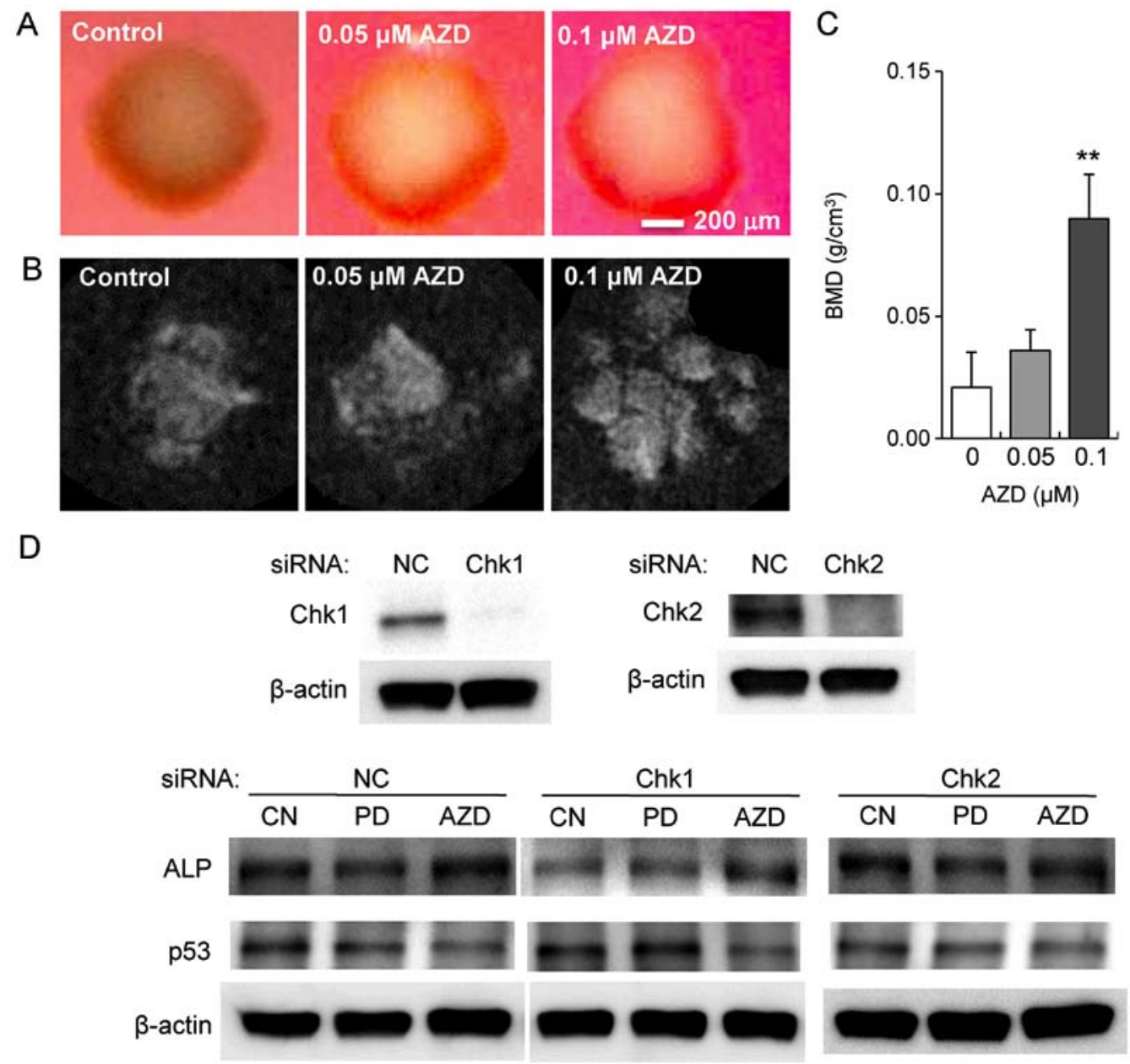

Figure 7. Mineralization of MC3T3 osteoblast-like cells and MLO-A5 osteocyte-like cells by AZD7762. (A) Optical and (B) microCT-derived X-ray images of mineralized spheroids from MLO-A5 osteocyte-like cells in response to 0.05 and $0.1 \mu \mathrm{M}$ AZD7762 for 2 weeks. (C) BMD of MLO-A5 spheroid constructs derived using microCT volumetric reconstruction. (D) Modulation of the response to PD407824 and AZD7762 by Chk1 and Chk2 siRNA in the protein level of ALP and p53. ${ }^{* *} \mathrm{P}<0.01$ vs. $0 \mu \mathrm{M}$ AZD. CN, control; AZD, AZD7762; PD, PD407824; BMD, bone mineral density; CT, computed tomography; Chk, checkpoint kinase; siRNA, small interfering RNA; ALP, alkaline phosphatase; p53, cellular tumor antigen; NC, negative control.

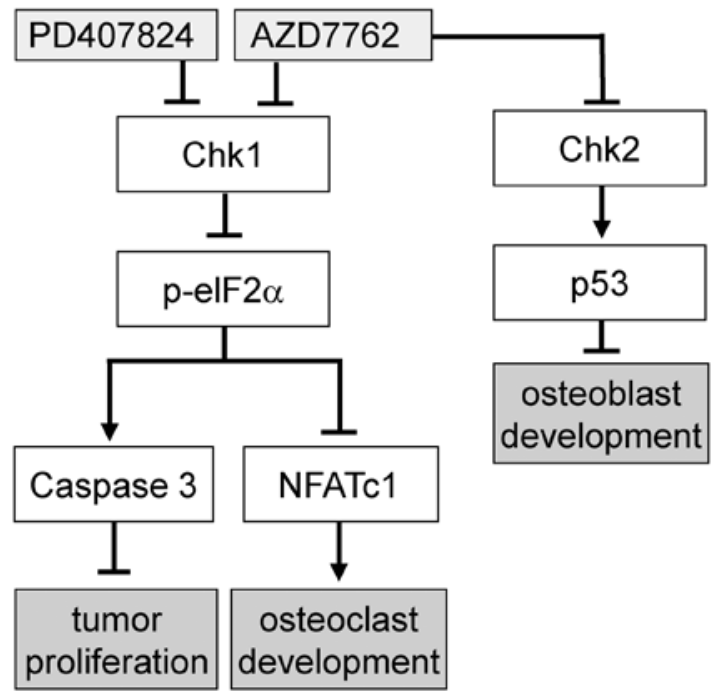

Figure 8. Schematic representation of the regulatory mechanism of AZD7762 via Chk1 and Chk2 signaling. AZD7762 and PD407824 inhibit Chk1 to suppress tumor proliferation and osteoclast development. AZD7762, and not PD407824, inhibits Chk2 to stimulate osteoblast development through p53 signaling. Chk, checkpoint kinase; NFATc1, nuclear factor of activated T cells cytoplasmic 1 ; p-eIF $2 \alpha$, phosphorylated eukaryotic translation initiation factor- $\alpha$; p53, cellular tumor antigen p53.
The present study demonstrated that AZD7762 serves an inhibitory role in bone-resorbing osteoclasts. To examine its role in bone-forming osteoblasts, Alizarin red staining was performed using MC3T3 cells. The results demonstrated that in response to $0.05,0.1$ and $0.5 \mu \mathrm{M}$ AZD7762 for 5 weeks, staining intensity was elevated in a dose-dependent manner (Fig. 6F and G). It was also observed that AZD7762 decreased the expression of p53 (Fig. 6H). Furthermore, 3D bone constructs with MLO-A5 osteocyte-like cell spheroids were bio-printed, and X-ray imaging was conducted after a 2 -week incubation in osteogenic medium. The results revealed that bone mineral density was elevated in response to 0.05 and $0.1 \mu \mathrm{M}$ AZD7762 (Fig. 7A-C). To evaluate the mediators of the differential effects of AZD7762 and PD407824 on p53 expression, partial silencing of Chk1 and Chk2 was conducted via siRNA in MC3T3 cells. Following silencing of Chk2, the AZD7762-mediated upregulation of ALP and downregulation of p53 were muted. However, the same alterations were not observed in Chk1-silenced cells (Fig. 7D). A proposed regulatory mechanism for AZD7762 is illustrated in Fig. 8, in which Chk1 and Chk2 are inhibited by AZD7762, as opposed to only Chk1 inhibition by PD407824. 


\section{Discussion}

The present study demonstrated that the Chk1 and Chk2 inhibitor AZD7762 suppressed tumor cell proliferation, inhibited osteoclast activity and stimulated osteoblast mineralization. Treatment with AZD7762 decreased the proliferation and spheroid formation of three different breast cancer cell lines (4T1.2, MDA-MB-231 and MCF-7). The 4T1.2 and MDA-MB231 cell lines are metastatic and estrogen receptor-negative, while MCF-7 cells are non-metastatic and estrogen receptorpositive. Treatment with AZD7762 decreased the size and 3D cell viability of $4 \mathrm{TT} 1.2$ spheroids in a dose-dependent manner. The inhibitory effect of AZD7762 was associated with the elevated protein expression of an apoptotic marker (caspase 3) and an autophagic marker (LC3A/BII). Of note, the role of autophagy is complex, and it is currently considered to function in tumor suppression and as a protective cell survival mechanism (34).

AZD7762 and PD407824 suppressed the 2D motility of 4T1.2 cells in the wound healing assay, although the apparent reduction of motility was also due to cell death. The reduction in RhoA GTPase activity by AZD7762 and PD407824 was consistent with their inactivation of cellular motility. The inhibitory effects of these two agents were evident without simultaneous application of DNA damaging agents. It has been reported that the effect of Chk inhibition on tumor growth may be dependent on the expression of and mutations in p53 and/or p21 (7). It was previously identified that inhibitors of eIF $2 \alpha$ de-phosphorylation (salubrinal and guanabenz) may suppress tumor proliferation and osteoclast differentiation $(14,15)$. In the present study, p-eIF2 $\alpha$ was upregulated by AZD7762 and PD407824. Due to the observed upregulation of p-PERK, one possibility is that Chk1 and Chk2 inhibitors induce stress to the ER and elevate p-PERK and p-eIF2 $\alpha$ expression. It is also possible that other kinases or phosphatases may be involved in the regulation of p-eIF $2 \alpha$.

Similar to its effects on tumor cells, AZD7762 also inhibited the proliferation of RAW264.7 pre-osteoclast cells in monolayer cultures and in 3D spheroids. Staining of TRAP-positive multi-nucleated osteoclasts and measuring the resorbed mineral area demonstrated that RANKL-induced osteoclast differentiation and activity was inhibited by treatment with AZD7762 in a dose-dependent manner. Treatment with AZD7762 also decreased the protein expression of NFATc1, a master transcription factor of osteoclastogenesis, and cathepsin $\mathrm{K}$, a protease involved in bone resorption, while increasing the phosphorylation of eIF $2 \alpha$ and the expression of cleaved caspase 3. PD407824 also decreased osteoclast differentiation. Metastatic tumor cells that invade the bone may accelerate osteoclast-driven bone resorption, triggering a dangerous cycle (35). These results demonstrated that targeting Chk signaling may provide a way to slow tumor growth and metastasis-associated bone degradation.

While the effects of AZD7762 and PD407824 on tumor cells and osteoclast cells were similar, their effects on osteoblasts diverged. AZD7762 upregulated the mRNA expression levels of bone the formation markers osterix and ALP, while PD407824 downregulated their mRNA expression levels. Furthermore, AZD7762 elevated the protein expression level of p-p38 and reduced that of p53, and PD407824 did not significantly alter the levels of p-p38 or p53. RNA interference of Chk1 and Chk2 in osteoblasts suggested that this difference may have been caused by the inhibitory effect of AZD7762 on Chk2, thereby downregulating p53 (23), a negative regulator of osterix (24). Therefore, targeting Chk2 may be a way to attenuate bone degradation caused by metastasis. However, p53 is also a tumor suppressor (36), and the p53-dependent effects of the inhibitory effect ofAZD7762 on tumor growth and bone remodeling via Chk2 require further study. A previous study indicated the complexity of the action of p53 as a crucial tumor suppressor, in addition to as a modulator of stem cell maintenance, invasion and metastasis (37).

While the present results revealed a novel role for AZD7762 in bone remodeling and bone metastasis, the present study has certain limitations. The experiments herein employed mouse and human cell lines (11), and gene expression was primarily examined using monolayer cell cultures. Although clinical trials of AZD7762 are not going forward due to unpredictable cardiac toxicity, inhibition of Chk remains an important therapeutic target (38). Future work may aim to identify other Chk inhibitors that exhibit similar effects to AZD7762, and test their efficacy in a mouse model of bone metastasis. In conclusion, the present study demonstrated that Chk1/2 inhibitors may be used to suppress tumor proliferation and to prevent bone loss via inhibition of osteoclastogenesis and stimulation of osteoblastogenesis.

\section{Acknowledgements}

The authors would like to thank Ms. T. Truong Vo for technical support.

\section{Funding}

The present study was supported in part by funds from the breast cancer advocacy group 100 Voices of Hope.

\section{Availability of data and materials}

The datasets used and/or analyzed during the current study are available from the corresponding author on reasonable request.

\section{Author contributions}

SN, HN, BYL and HY were involved in the conception of the study and the experimental design. LW, YW, AC, AJ, SL and YG were involved in data collection and interpretation. AC, BYL and HY drafted the manuscript.

\section{Ethics approval and consent to participate}

Experimental procedures involving animals were approved by the Indiana University Animal Care and Use Committee in compliance with the Guiding Principles in the Care and Use of Animals endorsed by the American Physiological Society.

\section{Patient consent for publication}

Not applicable. 


\section{Competing interests}

The authors declare that they have no competing interests.

\section{References}

1. Smits VA and Gillespie DA: DNA damage control: Regulation and functions of checkpoint kinase 1. FEBS J 282: 3681-3692, 2015.

2. Sanchez Y, Wong C, Thoma RS, Richman R, Wu Z, Piwnica-Worms $\mathrm{H}$ and Elledge SJ: Conservation of the Chk1 checkpoint pathway in mammals: Linkage of DNA damage to Cdk regulation through Cdc25. Science 277: 1497-1501, 1997.

3. Narayanaswamy PB, Tkachuk S, Haller H, Dumler I and Kiyan Y: CHK1 and RAD51 activation after DNA damage is regulated via urokinase receptor/TLR4 signaling. Cell Death Dis 7: e2383, 2016

4. McNeely S, Beckmann R and Bence Lin AK: CHEK again: Revisiting the development of CHK1 inhibitors for cancer therapy. Pharmacol Ther 142: 1-10, 2014.

5. Kuo C-Y, Zupkó I, Chang F-R, Hunyadi A, Wu C-C, Weng T-S and Wang H-C: Dietary flavonoid derivatives enhance chemotherapeutic effect by inhibiting the DNA damage response pathway. Toxicol Appl Pharmacol 311: 99-105, 2016.

6. Massey AJ, Stokes S, Browne H, Foloppe N, Fiumana A, Scrace S Fallowfield M, Bedford S, Webb P, Baker L, et al: Identification of novel, in vivo active Chk1 inhibitors utilizing structure guided drug design. Oncotarget 6: 35797-35812, 2015.

7. Origanti S, Cai SR, Munir AZ, White LS and Piwnica-Worms H: Synthetic lethality of Chk1 inhibition combined with p53 and/or p21 loss during a DNA damage response in normal and tumor cells. Oncogene 32: 577-588, 2013.

8. Gokulnath M, Swetha R, Thejaswini G, Shilpa P and Selvamurugan N: Transforming growth factor- $\beta 1$ regulation of ATF-3, c-Jun and JunB proteins for activation of matrix metalloproteinase-13 gene in human breast cancer cells. Int J Biol Macromol 94: 370-377, 2017.

9. Zabludoff SD, Deng C, Grondine MR, Sheehy AM, Ashwell S, Caleb BL, Green S, Haye HR, Horn CL, Janetka JW, et al AZD7762, a novel checkpoint kinase inhibitor, drives checkpoint abrogation and potentiates DNA-targeted therapies. Mol Cancer Ther 7: 2955-2966, 2008

10. Azorsa DO, Gonzales IM, Basu GD, Choudhary A, Arora S, Bisanz KM, Kiefer JA, Henderson MC, Trent JM, Von Hoff DD, et al: Synthetic lethal RNAi screening identifies sensitizing targets for gemcitabine therapy in pancreatic cancer. J Transl Med 7: 43, 2009.

11. Liu S, Liu Y, Minami K, Chen A, Wan Q, Yin Y, Gan L, Xu A Matsuura N, Koizumi M, et al: Inhibiting checkpoint kinase 1 protects bone from bone resorption by mammary tumor in a mouse model. Oncotarget 9: 9364-9378, 2018.

12. Zannini L, Delia D and Buscemi G: CHK2 kinase in the DNA damage response and beyond. J Mol Cell Biol 6: 442-457, 2014.

13. Wu X, Webster SR and Chen J: Characterization of tumorassociated Chk2 mutations. J Biol Chem 276: 2971-2974, 2001.

14. Hamamura K, Minami K, Tanjung N, Wan Q, Koizumi M, Matsuura N, Na S and Yokota H: Attenuation of malignant phenotypes of breast cancer cells through eIF $2 \alpha$-mediated downregulation of Rac1 signaling. Int J Oncol 44: 1980-1988, 2014.

15. Hamamura K, Tanjung N and Yokota H: Suppression of osteoclastogenesis through phosphorylation of eukaryotic translation initiation factor 2 alpha. J Bone Miner Metab 31: 618-628, 2013.

16. Liu Z, Lv Y, Zhao N, Guan G and Wang J: Protein kinase R-like ER kinase and its role in endoplasmic reticulum stress-decided cell fate. Cell Death Dis 6: e1822, 2015.

17. Raschke WC, Baird S, Ralph P and Nakoinz I: Functional macrophage cell lines transformed by Abelson leukemia virus. Cell 15: 261-267, 1978.

18. Wang D, Christensen K, Chawla K, Xiao G, Krebsbach PH and Franceschi RT: Isolation and characterization of MC3T3-E1 preosteoblast subclones with distinct in vitro and in vivo differentiation/mineralization potential. J Bone Miner Res 14: 893-903, 1999

19. Kato Y,Boskey A, Spevak L, Dallas M, Hori M and Bonewald LF: Establishment of an osteoid preosteocyte-like cell MLO-A5 that spontaneously mineralizes in culture. J Bone Miner Res 16 : $1622-1633,2001$
20. Lelekakis M, Moseley JM, Martin TJ, Hards D, Williams E, Ho P, Lowen D, Javni J, Miller FR, Slavin J, et al: A novel orthotopic model of breast cancer metastasis to bone. Clin Exp Metastasis 17: 163-170, 1999.

21. Chen A, Wang L, Li B-Y, Sherman J, Ryu JE, Hamamura K, Liu Y, Nakshatri H and Yokota H: Reduction in migratory phenotype in a metastasized breast cancer cell line via downregulation of S100A4 and GRM3. Sci Rep 7: 3459, 2017.

22. Moldovan NI, Hibino N and Nakayama K: Principles of the Kenzan method for robotic cell spheroid-based three-dimensional bioprinting. Tissue Eng Part B Rev 23: 237-244, 2017.

23. Hirao A, Kong YY, Matsuoka S, Wakeham A, Ruland J, Yoshida H, Liu D, Elledge SJ and Mak TW: DNA damageinduced activation of $\mathrm{p} 53$ by the checkpoint kinase Chk2. Science 287: 1824-1827, 2000.

24. Wang X, Kua H-Y, Hu Y, Guo K, Zeng Q, Wu Q, Ng HH, Karsenty G, de Crombrugghe B, Yeh J, et al: p53 functions as a negative regulator of osteoblastogenesis, osteoblast-dependent osteoclastogenesis, and bone remodeling. J Cell Biol 172: $115-125,2006$.

25. Cailleau R, Young R, Olivé M and Reeves WJ Jr: Breast tumor cell lines from pleural effusions. J Natl Cancer Inst 53: 661-674, 1974.

26. Soule HD, Vazguez J, Long A, Albert S and Brennan M: A human cell line from a pleural effusion derived from a breast carcinoma. J Natl Cancer Inst 51: 1409-1416, 1973.

27. Yokota H, Hamamura K, Chen A, Dodge TR, Tanjung N, Abedinpoor A and Zhang P: Effects of salubrinal on development of osteoclasts and osteoblasts from bone marrow-derived cells. BMC Musculoskelet Disord 14: 197, 2013.

28. National Research Council (US) Committee: Guide for the Care and Use of Laboratory Animals. 8th edition. National Academies Press, Washington, DC, 2011.

29. Ascione F, Vasaturo A, Caserta S, D'Esposito V, Formisano P and Guido S: Comparison between fibroblast wound healing and cell random migration assays in vitro. Exp Cell Res 347: 123-132, 2016.

30. Zhang J, Zhu L and Peng B: Effect of BioAggregate on osteoclast differentiation and inflammatory bone resorption in vivo. Int Endod J 48: 1077-1085, 2015.

31. Miyazaki T, Miyauchi S, Anada T, Imaizumi H and Suzuki O: Evaluation of osteoclastic resorption activity using calcium phosphate coating combined with labeled polyanion. Anal Biochem 410: 7-12, 2011.

32. Hamamura K, Swarnkar G, Tanjung N, Cho E, Li J, Na S and Yokota H: RhoA-mediated signaling in mechanotransduction of osteoblasts. Connect Tissue Res 53: 398-406, 2012.

33. Wei W, Clockaerts S, Bastiaansen-Jenniskens YM, Gierman LM, Botter SM, Bierma-Zeinstra SM, Weinans H, Verhaar JA, Kloppenburg M,Zuurmond AM, et al: Statins and fibrates do not affect development of spontaneous cartilage damage in STR/Ort mice. Osteoarthritis Cartilage 22: 293-301, 2014.

34. Dalby KN, Tekedereli I, Lopez-Berestein G and Ozpolat B: Targeting the prodeath and prosurvival functions of autophagy as novel therapeutic strategies in cancer. Autophagy 6: 322-329, 2010.

35. Clezardin P and Teti A: Bone metastasis: Pathogenesis and therapeutic implications. Clin Exp Metastasis 24: 599-608, 2007.

36. Vogelstein B, Lane D and Levine AJ: Surfing the p53 network. Nature 408: 307-310, 2000.

37. Bieging KT, Mello SS and Attardi LD: Unravelling mechanisms of p53-mediated tumour suppression. Nat Rev Cancer 14: 359-370, 2014.

38. Sausville E, Lorusso P, Carducci M, Carter J, Quinn MF, Malburg L, Azad N, Cosgrove D, Knight R, Barker P, et al: Phase I dose-escalation study of AZD7762, a checkpoint kinase inhibitor, in combination with gemcitabine in US patients with advanced solid tumors. Cancer Chemother Pharmacol 73: $539-549,2014$. 